\title{
HIPÓTESIS DE CONFLICTO Y CASUS NECESSITATIS: TOMÁS DE AQUINO, EGIDIO ROMANO Y GUILLERMO DE OCKHAM
}

Francisco Bertelloni*

SÍNTESE - Três autores medievais são aqui examinados a respeito da questão da normalidade e da exceção em teoria política. Tomás de Aquino escreveu sua obra voltada apenas para os casos de normalidade institucional. Egídio Romano pergunta-se sobre a caducidade da ordem institucional o surgimento do poder político originário no estado de exceçäo. Guilherme de Ockham trata da caducidade da ordem legal $\mathrm{e}$ do retomo à ordem do direito natural.

PALAVRAS-CHAVE: Política medieval. Tomás de Aquino. Egídio Romano. Guilherme de Ockham. Ordem institucional. Regime de exceção. Direito natural.
ABSTRÄCT - There medieval authors are examined here in connection with the question of normality and exception in political theory. Thomas Aquinas envisaged with his work only the cases oof institucional normality. Aegidius Romanus set out to investigate the obsolescence of the institucional order and the emergence of originary political power in the state of exception. William Ockham deals with the obsolescence of legal order and the return to the order of naturak law.

KEY WORDS - Medieval politics. Thomas Aquinas. Aegidius Romanus. William Ockham. Institutional order. Regime of exception. Natural law.

La reflexión política resultante de la recepción medieval de los libri morales de Aristoteles generó una literatura política que conocemos con el nombre de filosofía política. Ella estuvo orientada, de modo predominante, a garantizar lo que hoy podríamos llamar el orden constitucional, es decir un orden que debía actuar como garantía del desenvolvimiento de la vida política en situaciones normales y regulares. En cambio la reflexión política de esa misma época, basada no en los textos aristotélicos, sino en la tradición teológica medieval, generó una serie de doctrinas a partir de las cuales no solamente era posible la determinación de las condiciones de la vida política en situaciones normales. Además de ofrecer recursos teóricos para ser utilizados en situaciones de normalidad politica, ellas ofrecían recursos que posibilitaban su utilización tambien en las situaciones de anormalidad que llamados estados excepcionales.

\footnotetext{
Professor na Universidade de Buenos Aires.
}

\begin{tabular}{|l|l|l|l|l|l|}
\hline VERITAS & Porto Alegre & v. 45 & n. 3 & Setembro 2000 & p. $393-410$ \\
\hline
\end{tabular}


En ese trabajo analizaré brevemente tres textos de la literatura política de la baja edad media. El primero de ellos, el De regimine principum de Tomás de Aquino, servirá como prototipo de la teoría política surgida de la tradición filosófica aristotélica, pensada para casos regulares. El segundo, el De ecclesiastica potestate de Egidio Romano, constituye un paradigma de una teoría política construida a partir de la teología, que preve el funcionamiento de los poderes políticos en casos' de caducidad de las instituciones que deben funcionar en casos de normalidad. En el tercer caso analizaré sobre todo el Breviloquium de Guillermo de Ockham junto con otros textos del venerabiis inceptor. En este tercer caso intentaré mostrar que la estructura interna del pensamiento político de Ockham tambien preve recursos teóricos aplicables a los casos no regulares o de excepción.

\section{El De regimine principum de Tomás de Aquino: una teoría política pensada solo para casos de normalidad institucional}

Una rápida lectura del De regimine principum de Tomás de Aquino muestra la facilidad con que Tomás maneja los conceptos de la teoría política que surgía en esos años. Aunque toma muchos de esos conceptos de Aristóteles, a pesar de la autoridad del maestro Tomás se empeña en ofrecer su propia concepción acerca de ellos. Así presenta la sociedad como una relación horizontal entre los hombres, necesaria para conocer las cosas necesarias para la vida. Ella deriva de las falencias del hombre respecto de los animales, cuyos instrumentos naturales les permiten, instintivamente, vivir solos y encontrar por sí esas cosas necesarias para vivir. La política, en cambio, es una relación vertical de un hombre - el rey - con una multitud de hombres que le están subordinados en virtud de que debe conducirlos a todos a un mismo fin.

Para definir el fin de la multitud Tomás equipara el fin de esa multitud con el fin del individuo ${ }^{1}$ e identifica la virtud con ese fin. Pero afirma que esa virtud no puede ser otra que la que ordena al hombre a la visión divina. ${ }^{2} \mathrm{Si}$ los hombres se reunieran solo para vivir o para adquirir riquezas, el resultado de esa reunión no sería diferente de la vida de los animales o de un acuerdo entre hombres de negocios. ${ }^{3}$ Pero Tomás quiere más para la política. Por ello insiste en afirmar que el fin de la multitud es la vida virtuosa, bona vita est secundum virtutem. ${ }^{4}$

1 "Idem autem oportet esse iudicium de fine totius multitudinis, et unius" (cfr. De regimine principum, en Divi Thomae Aquinatis Opuscula Philosophica, cura et studio R. Spiazzi, Marietti, Roma, 1954, 816). Cito el número de párrafo de esta edición.

2 "Sed quia homo vivendo secundum virtutem ad ulteriorem finem ordinatur, qui consistit in fruitione divina [... $]^{n}(817)$.

3 "Si enim propter solum vivere homines convenirent, animalia et servi essent pars aliqua congregatonis civilis. Si vero propter adquirendas divitias, omnes simul negotiantes ad unam civitatem pertinerent [...]" (817).

"Videtur autem finis esse multitudinis congregatae vivere secundum virtutem. Ad hoc enim homines congregantur ut simul bene vivant, quod consequi non posset unusquisque singulariter vivens; bona autem vita est secundum virtutem; virtuosa igitur vita est congregationis humanae finis" (817). 
¿Qué significa para Tomás vita secundum virtutem? Aunque el fin de la multitud es la vida virtuosa, Tomás aclara que esa vida no es su fin último. La vida según la virtud es el paradigma de la vida en común que debe estar al cuidado del gobernante temporal. Pero esa vida según la virtud no es el fin último de la vida de la multitud. El fin último consiste en la fruitio Dei de la vida futura. Así, en la medida en que la multitud debe vivir según la virtud guiada a ella por el gobemante, la virtud está atada al mundo natural. Pero al mismo tiempo, en la medida en que esa misma virtud está ordenada ad ulteriorem finem, ella tiene la potencia de superar el mundo natural y conducir los hombres a la vida sobrenatural.

¿Qué relaciones hay entre la vita secundum virtutem y la política? Aunque el fin de la multitudo congregata es vivere secundum virtutem, ${ }^{5}$ sin embargo ese vivere no es suficiente para legitimar la especificidad y autonomía del orden socio-político temporal. Por ello ese mismo vivere secundum virtutem debe posibilitar el salto a un fin ulterior consistente en la fruitio Dei. ${ }^{6}$ De allí que el fin último de la vida política no sea vivir según la virtud sino, mediante esa virtud, llegar a la visión de Dios. Tomás no juega con las palabras. Su posición es clarísima cuando escribe: "El fin último de la vida en común [multitudo congregata] no es vivir según la virtud, sino llegar, por medio de la vida virtuosa, al gozo de Dios"?

De esta definición surge el carácter casi unipolar de la teleología política tomista. Ella gira en tomo de una vida virtuosa bidimensional: está anclada al mundo natural, pero no tiene su fin último ni logra su plena realización en el orden natural. La vida virtuosa de la multitudo oculta la paradoja de ser una vida según una virtud natural, cuya función es conducimos al mundo sobrenatural. Así, el orden político natural - representado por la vida virtuosa - no tiene un fin último específico, propio y último, de realización autónoma en el mundo natural. El fin del orden político está sólidamente anudado y subordinado a nuestra salvación en la vida futura. Así, vida política y vida sobrenatural guardan la misma relación que hay entre fin y fin último.

¿Cómo procede Tomás para vincular metafísicamente la vida virtuosa como fin de la multitudo congregata con el fin último al que, mediante esa vida virtuosa, debe ser conducida la multitudo congregata?. No voy a reconstruir aquí en detalle los fundamentos metafísicos de la teoría política de Tomás. ${ }^{8}$ Sólo conviene recor-

\footnotetext{
Como nota 4.

"[...] homo vivendo secundum virtutem ad ulteriorem finem ordinatur, qui consistit in fruitione divina [...]" (818).

"Non est ergo ultimus finis multitudinis congregatae vivere secundum virtutem, sed per virtuosam vitam pervenire ad fruitionem divinam" (817). El destacado es mío.

Tal como está presentado en la Summa contra Gentiles, III, 39. Alli Tomás trata el problema del conocimiento como fin último natural del hombre en términos absolutamente teleológicos y de causalidad final. Paradojalmente, ese fin último natural que el hombre desea satisfacer poniendo en acto toda la potencia posible de su intelecto no encuentra su satisfacción ni su cumplimiento en el orden natural, sino recién en la contemplación que en el mundo sobrenatural y en la vida futura podemos tener de Dios, que es lo máximo inteligible (STh. I-Ilae, q. 5, a 3). En otros términos, del mismo modo como la vida según la virtud de la multitudo congregata es un fin, pero no es un fin último, así tambien el deseo natural de conocimiento es un fin del hombre, pero no su fin último, porque el intelecto humano está en potencia hacia todo lo inteligible ( $\mathrm{ScG}, \mathrm{III}, 39)$, y la actualización de esa potencia natural abierta a todo lo inteligible no puede ser alcanzada por el hombre en esta vida por medios naturales, sino en la vida futura por medio de la gracia (STh., I-Ilae, q.5, a .3).
} 
dar que la tesis política, según la cual el último fin de la multitudo congregata no es vivir según la virtud, sino llegar, por medio de la vida virtuosa, a la fruitio Dei, tiene su paralelo filosófico en una formulación de Tomás que expresa la realización última del fin del hombre en términos ético-antropológicos:

"Para alcanzar la felicidad humana, es decir el último fin [del hombre], no es suficiente cualquier conocimiento intelectual, sino tiene lugar el [nuestro] conocimiento divino [i. e.de Dios] que culmina nuestro deseo natural como su fin último. El último fin del hombre es, pues, el conocimiento de Dios mismo".

En otros términos, así como el fin natural del hombre no se realiza naturalmente sino sobrenaturalmente, así el fin de la vida política no se realiza políticamente sino teológicamente. Ahora podemos preguntar: ¿quién es el protagonista de este programa de gobierno político-teológico? La literatura política medieval suele ser un género muy polémico, sobre todo cuando ella discute sobre los fines del hombre. Y tanto más polémica es cuanto más último pretende ser el fin acerca del que discute. El motivo es simple: los poderes existentes se disputaban en la edad media la jurisdicción solo sobre los fines considerados últimos, pues éstos fines últimos siempre tienen carácter de fin respecto de los fines anteriores. Pretender jurisdicción sobre un fin no-último en su orden era abrir el camino a que quien tiene jurisdicción sobre ese fin no-último se transforme en un poder subordinado al poder que tiene jurisdicción sobre el fin último. La subordinación entre los poderes se deriva de la subordinación de los fines no-últimos a los fines últimos. Tener jurisdicción sobre los fines últimos es sinónimo de tener jurisdicción sobre los poderes con jurisdicción sobre los fines no-últimos. Pues existe una relación directamente proporcional entre la excelencia del poder y el carácter último del fin. Cuanto más excelente es un poder, tanta más jurisdicción puede pretender sobre el fin último.

Tomás distingue con prolijidad entre la vida presente y la vida futura y entre las funciones del gobierno temporal y las del sacerdote. Existe una vida que los hombres pueden vivir bien en este mundo; ${ }^{10}$ ella está a cargo del regimen humanum $^{11} \mathrm{u}$ officium regis. ${ }^{12}$ Tomás no niega la legitimidad ni la especificidad del officium regis, sino que dedica cuatro capítulos del Libro II a describir en detalle sus funciones. ${ }^{13}$ Pero aunque el rey tiene a su cargo un extenso repertorio de funciones, ellas se ordenan a conducir los súbditos hacia la visión divina por medio de la vida virtuosa. La regla de oro de Tomás sigue siendo que "el fin último de la multitudo congregata no es vivir según la virtud, sino llegar, por medio de la vida vir-

\footnotetext{
9 "Non sufficit igitur ad felicitatem humanam, quae est ultimus finis; qualiscumque intelligibilis cognitio, nisi divina cognitio adsit, quae terminat naturale desiderium sicut ultimus finis. Est ergo ultimus finis hominis ipsa Dei cognitio" (SCG, III,25, 2066).

"[...] vita, qua hic homines bene vivunt [...]" $(S c G, 822)$.

SCG, 818 .

"Quia igitur vitae, qua in presenti bene vivimus...ad regis officium pertineat [...]" (823).

En la edición Marietti (ut supra, nota 1) 829 a 846.
} 
tuosa, al gozo de Dios". ${ }^{14} \mathrm{Si}$ la función del gobernante temporal es gobernar a sus súbditos para que vivan según la virtud, esa función no se agota en promover la vida virtuosa en ese mundo, sino en facilitar, por medio de esa vida virtuosa, la visión divina en el mundo futuro.

¿Cuál es el objetivo de Tomás? A pesar del título del tratado, a Tomás no le interesa tanto definir el officium regis en este mundo, sino definir el lugar de ese officium regis dentro de la economía general del gobierno que debe conducir a los hombres hacia sus fines en el otro mundo. Dentro de esa economía general, el officium regis se transforma en un medio subordinado a las funciones de un gobierno divino que, ya en este mundo, prepara el camino para llegar al mundo futuro. No solo la referencia de Tomás a este gobierno divino es inmediata: es Cristo ${ }^{15}$ o, en la actual situación histórica de la humanidad, su vicario, el Papa. ${ }^{16}$ Además, Tomás introduce con rapidez su conclusión sobre las relaciones entre el gobiemo divino y el humano: "quienes tienen a su cuidado los fines anteriores deben subordinarse a aquél a quien concierne el gobierno de los fines últimos". ${ }^{17}$

Aunque el planteo tomista no neutraliza la posibilidad de polémica entre poderes, sin embargo no preve la posibilidad de un conflicto en el que, por ejemplo, haya colisión entre las funciones que su planteo atribuye al poder temporal y al espiritual. Tomás no preve qué sucedería si, dentro de su esquema de subordinación de poderes, el poder temporal ejerce su jurisdicción sobre el orden temporal alterando el esquema de subordinación de fines antecedentes a fines consecuentes. Ello sucedería, por ejemplo, si el gobiemo temporal fallara en sus funciones o no cumpliera su officium de preparar la multitudo congregata para vivir la vita secundum virtutem que, su vez debe conducirla a su fin último, la fruitio Dei.

Cuando escribe su texto (1265/7) Tomás sabe que la Cristiandad acaba de salir de un grave conflicto entre el Papado y el emperador Federico II, muerto en 1250. Sin embargo se limita a describir lo que debe suceder en situaciones normales, y no propone ningún esquema teórico que prevea situaciones excepcionales que alteren esa normalidad. Pero el diseño teórico de situaciones normales no basta para solucionar situaciones excepcionales. ¿Puede en ese caso el poder espiritual asumir directamente la potestas in temporalibus y neutralizar la competencia de la potestas temporalis?

"Sic enim ei, ad quem finis ultimi cura pertinet, subdi debent illi, ad quos pertinet cura antecedentium finium, et eius imperio dirigi [... $]^{n}$ (819). 


\section{El De ecclesiastica potestate de Egidio Romano: caducidad del orden institucional y surgimiento del poder político originario en el estado de excepción (casus imminens)}

No fue Tomás, sino un discípulo de Tomás, Egidio Romano, quien años mas tarde, respondió estas preguntas. En el tratado De ecclesiastica potestate (1302), Egidio recurre a un argumento que toma del tratado De angelica hierarchia del Pseudo Dionisio. Egidio afirma que la realidad está organizada de modo tal que en ella se verifica una reducción de lo inferior a lo superior mediante intermediarios. ${ }^{18}$ Con ese argumento no procura fundamentar la subordinación de los poderes temporales a la Iglesia - pues presupone esa subordinación - sino el modo, i.e. estructura metafísica según la cual tiene lugar esa subordinación. Egidio insiste especialmente sobre el aspecto mediatizado de la reducción: ella es y debe ser gradual y debe tener lugar de modo tal que lo inferior sea reducido a lo superior no immediate, sino per media, ${ }^{19}$ i.e. a través de grados intermedios. Si no hubiera mediatización en el proceso de reducción de lo menos a lo más, no habría orden en el universo.

De inmediato Egidio recurre al principio de economía para preguntar cómo se justifica la existencia - tambien - del poder temporal si, a través de intermediarios, ese poder temporal es totalmente reducido al espinitual. Más aún, ¿si el Papa tiene dominio simpliciter, es decir absoluto sobre el orden temporal, ¿no bastaría acaso con la sola existencia del poder espiritual para actuar directamente sobre el orden temporal? ¿Si el poder espiritual se extiende a todo, no bastaría con la existencia de una sola espada? ${ }^{20}$ ¿Para qué dos poderes, si basta con uno?

Egidio responde que la justificación de la existencia del poder temporal, además del espiritual, pasa por la diferencia entre el ejercicio de la potestas simpliciter y specialiter. De modo absoluto o simpliciter, la potestas spiritualis alcanza a toda la realidad, aunque specialiter, esto es de modo particular, cada una de esas potestates se ocupa de ámbitos diferentes de la realidad. Lo que permite establecer la diferencia entre poder absoluto o instituyente y poder limitado o instituído es, precisamente, la diferencia entre una potestas ejercida simpliciter y otra ejercida specialiter. ${ }^{21}$ Egidio agudiza esa diferencia para llegar a establecer la relación metafísica entre ambos poderes. En esa agudización aparece la especificidad que

18 "Possumus enim ex ordine universi hoc liquido declarare, quod super gentes et regna sit ecclesia constituta. Nam secundum Dionysium in De Angelica Ierarchia lex divinitatis est infima in suprema per media reducere. Hoc ergo requirit ordo universi, ut infima in suprema per media reducantur" (cfr. Aegidius Romanus, De ecclesiastica potestate, ed. de Richard Scholz, Aalen, 1961, p. 12). El destacado es mio.

19 "Si enim eque immediate infima reducerentur in suprema, sicut et media, non esset universum recte ordinatum [...]" (p. 12).

20 "[...] quia cum potestas spiritualis extendat se ad omnia et iudicet omnia, non solum animas, sed eciam corpora et res exteriores, videtur, quod unus solus gladius sufficiat" (p. 112).

21 "[...] cum due potestates sic se habent, quod una est generalis et extensa, alia particularis et contracta, oportet, quod una sit sub altera, sit instituta per alteram et agat ex commissine alterius vel in virtute alterius" (p. 113). 
caracteriza el pensamiento político de Egidio. Para ello recurre a un ejemplo: en la generación del caballo coactúan dos potestates: una potestas celestis o potestas generalis y otra, que está en el semen del caballo, que podríamos llamar potestas particularis. ${ }^{22}$ A pesar de que esta última coactúa con la potestas celestis en la generación del caballo, ella misma sería incapaz de generar el caballo si la fuerza (virtus) que está en el semen no hubiera sido recibida de la virtus por excelencia o virtus celestis presente en la potestas celestis o generalis.

Egidio insiste en la objeción referida a la justificación de la existencia de dos poderes cuando bastaría uno para hacer la tarea que hacen los dos. En su respuesta recurre al principio de funcionalidad: si en la Iglesia existiera solo la espada espiritual, ésta debería ocuparse de cosas materiales y ello redundaría en perjuicio de la eficiencia de la espada espiritual en el orden exclusivamente espiritual. ${ }^{23}$

En sintesis: en la realidad todos los poderes se reducen a un poder superior mediante intermediarios. Si se pregunta porqué hay más de un poder si todos se reducen a uno, la respuesta no pasa por la incapacidad del poder superior, sino por la conveniencia de que el superior actúe por medio de poderes inferiores. Es lo que ocurre en casos normales, pero no en casos excepcionales. Mientras en casos normales la espada material se ocupa de cosas materiales, sin embargo, si el caso lo urge o si la situación excepcional lo exige, la espada espiritual puede ocuparse de las cosas materiales de las cuales, en casos normales, se ocupa solamente la espada material. ${ }^{24}$ Pero no por existir la espada espiritual, que es superior y de más alcance que la material, ésta deja de existir o de cumplir sus funciones. ${ }^{25}$ La función de la espada material está prevista para casos normales y caduca solo en caso de excepción. En términos de Egidio: si casus immineat.

El lenguaje de Egidio sugiere que incluso es preferible y mejor que - además de la espada espiritual que puede todo - exista tambien la espada material. ${ }^{26}$ Pero su argumentación descarta absolutamente que dicha existencia se justifique en el hecho de que la espada espiritual pueda con la material algo que no podría sin ella, ${ }^{27}$ pues en ese caso habría algún poder en las cosas inferiores que no habría en las superiores, ${ }^{28}$ afirmación desmentida por el hecho de que a la Iglesia fueron confiados

22 Egidio no usa potestas particulanis, sino solo potestas. Hemos añadido particularis para distinguirla con claridad de la generalis.

23 "[...] verum est, si potest fieri per illud unum eque bene et eque decenter; sed si non esset nisi unus gladius in ecclesia, videlicet spiritualis, ea quae agenda essent in gubemacione hominum non fierent eque bene, quia exinde spiritualis gladius multa obmitteret que agenda essent circa spiritualia, ex eo quod oporteret ipsum intendere circa materialia" (p. 115).

"Non dicimus autem, quod si casus immineat, quod non possit spiritualis gladius circa materialia intendere [...]. Quod ergo institutus est secundus gladius, non est propter impotenciam spiritualis gladii, sed ex bona ordinacione et ex decencia" (p. 115). "[...] nec tamen propter potestatem spiritualem, que est generalis, superfluit potestas terrena, que est contracta et particularis" (p. 117). "[...] que sit necessitas ponendi materialem gladium, cum dictum sit, quod spiritualis gladius cuncta potest". (p. 129). "[...] quoniam aliquid potest superior cum potestate inferiori [...] quod non potest sine ill[a] [...]" (p. 129).

28 "I...] quia aliqua potestas potest esse in inferioribus que non est in superioribus nec a superioribus [...]" (p. 135). 
al mismo tiempo ambos poderes ${ }^{29}$ i.e. todo el poder. La preferencia de Egidio en favor de la existencia de dos espadas - y no solo de una - no reside en la presencia en la espada espiritual de algún minus que haría necesaria la existencia de un segundo poder complementario. De allí que toda la argumentación de Egidio se oriente a demostrar, no la necesidad esencial de la existencia de un segundo poder, sino solo la conveniencia de que ese segundo poder coactúe con la espada espiritual en beneficio de una mejor disposición del gobiemo del mundo. Esa mejor disposición, favorecida por la existencia de la espada material, hace que, en casos normales, ella no sea superflua.

Para apoyar esa mejor disposición ofrece varios argumentos. Egidio escribe que el último es el teóricamente más relevante: si no hubiera otros argumentos que justificaran la existencia de la espada temporal este solo argumento bastaría para justificarla. ${ }^{30}$ Para construirlo analoga la relación que existe entre Dios y las criaturas a la relación que existe entre la espada espiritual y la material. El argumento está basado en dos ideas. La primera es la omnipotencia divina: todo lo que Dios puede con la criatura lo puede tambien sin ella, puede calentar sin fuego y enfriar sin agua. ${ }^{31}$ La segunda idea es la superabundante bondad de Dios que quiere comunicar su propia dignidad a las creaturas ${ }^{32}$ de modo que éstas - y no solo Él - actúen como causas de las cosas. Por ello les concede la capacidad de actuar de modo tal que Dios obra en la realidad a través de ellas del mismo modo como podría hacerlo sin ellas. Análogamente, la espada espiritual recurre a la espada material para gobernar con ella y ejecutar, a través de ella, actos de gobierno que si fueran ejecutados directamente por ella, no serían ejecutados tan convenientemente como cuando los ejecuta a través de la espada material. Ésta, pues, no es superflua, sino que ejerce acciones propias que coactúan en el gobierno que la espada espiritual ejerce sobre los hombres.

La situación presentada por los argumentos precedentes crea un espacio para ambas espadas. Esa situación de ningún modo es presentada como una situación esencialmente $o$ cualitativamente diferente a la situación en la que todo el poder sería ejercido solamente por la espada espintual. Dos son las proposiciones claves en la construcción de su argumentación: (a) todo lo que la espada espiritual puede con la material lo puede tambien sin ella; (b) la existencia de la espada material como potestas no superflua se justifica porque ella puede hacer en la realidad de otro modo lo mismo que la espada espiritual puede hacer en la misma realidad directamente y simpliciter. De estas dos proposiciones solo la proposición (a) presenta una situación esencialmente inalterable, pues ella se refiere a la esencia de los poderes. En cambio la proposición (b) presenta una situación referida al modo de ejercicio de los

\footnotetext{
29 "[...] quia utrumque gladium habet ecclesia et utramque potestatem, sibique simul terreni et celestis iura imperii sunt commissa, extra quam non est salus [...]" (p. 135).

"[...] quod si nulla esset alia causa [...] hec [...] causa [...] est satis sufficiens" (p. 137).

“[...] quicquid potest Deus cum creatura, potest sine creatura [...]. Posset enim Deus calefacere sine igne, infrigidare sine aqua, salvare transfretantes et transeuntes mare sine ligno [...]" (p. 131).

"[...] superior vult inferioribus suam dignitatem communicare [...]; ut non essent supervacua opera sapiencie sue, voluit dignitatem suam communicare creaturis, et voluit, quod creature sue haberent acciones proprias et virtutes proprias et essent cause rerum [...]" (p. 131).
} 
poderes, acerca de cuya esencia e inalterabilidad - no acerca del modo de ejercitarlos - se expide la proposición (a). Así, la proposición (b) es inalterable en todo lo que ella reitera la proposición (a) o en todo aquello de la proposición (a) que está contenido en la (b); pero la (b) es alterable en todo lo que ella agrega o excede a la proposición (a) , i. e. en cuanto al modo como los poderes referidos por la proposición (a) son ejercidos en este mundo.

Egidio insiste una y otra vez en presentar la situación (b) (= el coejercicio de ambas espadas en el ejercicio del poder) como la situación normal de gobierno. Aquí aparece la gran paradoja de la política intuída por Egidio: la proposición (b) que expresa la situación normal de gobiemo, no coincide con (a), i. e. con la naturaleza esencial del poder que puede, sin la espada material, todo lo que puede con la espada material. Esa no coincidencia se deriva del hecho de que si bien puede ser alterado el modo de ejercicio normal del poder, no puede ser alterada la esencia del poder. El principio de alterabilidad del modo como el poder debe ser ejercido regular y normalmente se fundamenta en una gran paradoja: en lo que debe suceder normalmente $[=(b)]$ no se manifiesta la esencia del poder, sino solo uno de sus modos de ejercicio; por ello ese modo de ejercicio puede ser alterado; en cambio, en lo que sucede excepcionalmente $[=(a)]$, el poder se manifiesta en su esencia propia. Por ello (a) no puede ser alterada.

Frente a esta descripción la pregunta se impone: ¿cuándo puede ser alterada esa situación (b), de tal manera que la espada espiritual, ordenada por conveniencia solo a lo espiritual, se ocupe tambien de lo material? La respuesta de Egidio es rápida: en caso de excepción (si casus immineat). ${ }^{33}$

Como lo había hecho Tomás, tambien Egidio construye su argumentación politica sobre sólidos fundamentos teóricos.

Para ello recurre, en primer lugar, al modo de comportamiento de los agentes naturales en el universo y a la doble ley según la cual esos agentes son gobernados por Dios. Los agentes naturales pueden depender de Dios de dos modos. En virtud de una ley común de gobiemo de las cosas, Dios distribuye sus virtudes a todas las criaturas y a cada una de ellas, sin excepciones, da su fuerza propia y no obstaculiza la acción de ninguna, sino que permite a cada una que siga su propio curso; ${ }^{34}$ según esta ley Dios no hace excepciones, sino que actúa frente a cada cosa de modo común, uniforme y regular. ${ }^{35}$ En segundo lugar Egidio analoga a Dios con el Papa y a la doble ley de gobierno divino universal con el doble modo según el cual el Papa go-

33 "Nam quia spiritualis gladius est tam excellens et tam excellentia sunt sibi commissa, ut liberius possit eis vacare, adiunctus est sibi secundus gladius, ex cuius adiunccione in nullo diminuta est eius iurisdictio et plenitudo potestatis ipsius sed ad quantam decenciam hoc est factum, ut qui ordinatur ad magna, nisi casus immineat, non se intromittat per se ipsum et immediate de parvis" ( $p$. $145 \mathrm{~s}$.). El destacado es mío.

"Sic enim videmus in naturalibus, quod aliqua fiunt secundum communem legem gubernacionis rerum, aliqua vero secundum divinam dispensacionem et Dei providenciam specialem. Duplici ergo lege gubernatur mundus a Deo, communi et speciali. Secundum quidem communem legem gubernacionis mundi potest Deus assimilari [...] cuidam universali agenti. Quod universale agens omnibus rebus suas virtutes tribuit et nullam rem in sua accione impedit, sed omnes res proprios cursus agere sinit" (p. 150).

35 "Quod mare (= Deus) secundum communem legem se habet uniformiter ad omnia" (p. 151). 
biema la Iglesia . En cuanto gobierna la Iglesia siguiendo la ley común, el papa actúa uniformemente frente a cada uno de los miembros de esa Iglesia, ${ }^{36}$ conserva a cada uno en su estado, no impide el oficio de ninguno $0^{37} \mathrm{y}$, consecuentemente, no se entromete en los asuntos temporales que corresponden a los poderes temporales. ${ }^{38}$

Pero las cosas o agentes naturales pueden depender de Dios tambien según una ley especial, pues Dios tiene tal dominio universal sobre el mundo natural que con él puede hacer que el fuego no caliente o el agua no moje. ${ }^{39}$ Del mismo modo, el papa tiene un dominio universal sobre las cosas temporales, ${ }^{40} \mathrm{y}$ aunque según la ley común - que respeta en situaciones normales - no se entromete en lo temporal, el papa puede hacerlo - como lo hace Dios - en caso de que acontezca en ellas algo especial, excepcional, que exige su intervención directa in temporalibus. ${ }^{41}$ Esta intervención implicará - como sucede en el caso de que Dios intervenga más allá de la ley común - actuar más allá del normal curso de los acontecimientos. ${ }^{42}$

Más importante que las causales de intromisión, que no mencionaré aquí en detalle, es la referencia de Egidio a casos que - aunque en situaciones nomales aconsejan que el Papa respete la lex communis observando la jurisdicción de los poderes temporales - pueden transformarse en situaciones excepcionales que obligan al Papa a intervenir en el orden temporàl, es decir, no a través de los poderes por él instituidos para ello en casos normales, sino inmediata y excepcionalmente. ${ }^{43}$ Egidio procura resolver aquí dos problemas. El primero: ¿cómo es que las cosas temporales, que en virtud de su naturaleza temporal están sujetas al poder terrenal, pueden pasar a estar bajo jurisdicción del poder espiritual $?^{44}$ El segundo: ¿en qué casos tiene lugar esa transformación?

Para responder la segunda pregunta Egidio menciona diversos casos que, en mi opinión, pueden ser homogeneizados bajo un principio común: en todos esos casos las cosas temporales pueden ser llamadas espirituales. ${ }^{45}$ En otros términos, Egidio admite una cierta transmutación de la naturaleza de las cosas temporales que normalmente caen bajo la jurisdicción del poder temporal. Esa cierta transmutación permite llamarlas espirituales. Es en virtud de esa transmutación que puede tener lugar la intervención inmediata del papa en el orden temporal.

\footnotetext{
36 "Sicut ergo censendum est de Deo, prout secundum legem communem gubernat totum mundum, sic eciam censendum est de vicario Dei, prout secundum communem legem totam ecclesiam gubernat [...]" (p. 152). "[...] summus pontifex...secundum legem communem gubernat ecclesiam et ad omnia uniformiter se habet, quia omnia in suo statu conservat [...] nullum in suo officio impedit [...]" (p. 155).

"Secundum legem communem non intromittet se papa de temporalibus [...]" (p. 156).

"Nam sicut Deus habet universale dominium in omnibus rebus naturalibus, secundum quod dominium facere posset, quod ignis non combureret et aqua non madefaceret [...]" (p. 156).

"[...] ipse tamen secundum communem legem mundum gubernat [...]" (p. 156).

"[...] non intromittet se papa de temporalibus; sed secundum specialem legem [intromittet se] [...]"; "[...] nisi aliud speciale in talibus [rebus temporalibus] occurrat [...]" (p. 156).

"[...] Deus preter solitum cursum et preter communem legem velle aliqua operarin (p. 161).

"Fecimus autem mencionem de iurisdiccione immediata et executoria, quia iurisdiccionem superiorem et primariam semper et directe super temporalibus habet ecclesia" (p. 180).

"Dicimus eutem in certis casibus, quia ipsa temporalia secundum se et immediate ordinantur ad corpus [...] ex mandato tamen domini [spectat ad potestatem ecclesiasticam excercere temporalem iurisdiccionem]" (p. 179).

"In hiis ergo casibus ipsa temporalia possunt dici spiritualia" (p. 180).
} 
¿Cuándo se produce la transmutación? Egidio es terminante cuando debe justificar esa transmutación. Ella tiene lugar cuando la espada temporal es incompetente para administrar el orden temporal, cuando comete errores en su administración, ${ }^{46}$ o cuando es negligente ${ }^{47}$ o cuando los mismos hombres cometen faltas espirituales en relación con ellas. ${ }^{48}$ En estos casos se produce tal usurpación de las cosas temporales que ellas implican un mal para el espíritu que debe ser corregido por la espada espiritual. ${ }^{49}$ En síntesis, la justificación de la intervención inmediata del poder espiritual en lo temporal se basa en lo espiritual que está implicado en lo temporal. Puesto que lo espiritual implicado en lo temporal es más importante que lo temporal mismo en lo cual lo espiritual está implicado, la intervención excepcional del pontífice en lo temporal es más amplia y más importante que la intervención regulariter del señor temporal en lo temporal. ${ }^{50}$

Para precisar mejor la jurisdicción del papa in temporalibus, Egidio recurre a la distinción entre potestas absoluta y potestas regulata. Ella corresponde, a su vez, a la doble jurisdicción que el papa ejerce en el orden temporal. ${ }^{51}$ Según la potestas absoluta, el papa está por encima del orden jurídico positivo, según la potestas regulata, gobierna la Iglesia observando la validez de ese orden jurídico. ${ }^{52}$ De esta distinción resulta una doble jurisdicción en el orden temporal: una regular que ejerce sobre todo el orden temporal, otra casual ejercida bajo ciertas circunstancias. $^{53}$

En la concepción de Egidio, el poder del papa se extiende ad omnia. ${ }^{54}$ La formulación técnica que asume esa potestas ad omnia del papa es plenitudo potestatis. Hasta aquí Egidio se refirió a esa plenitudo potestatis en términos de jurisdicción. Ahora lo hará en términos de causalidad: Ante la pregunta ¿quid est plenitudo potestatis? Egidio formula una definición de plenitudo potestatis. Primero lo hace en términos positivos: tiene plenitud de poder cualquier agente que puede efectuar sin causa segunda todo lo que puede con la causa segunda ${ }^{55}$ Fundamen-

\footnotetext{
46 "[...] ut si ipse gladius materialis delinquat circa temporalia et eciam gubernacula sibi commissa, ex culpa materialis gladii vel eciam ex causa poterit spiritualis gladius animadvertere in ipsum" (p. 180).

47 "[...] si huiusmodi materialis gladius sit negligens et negligat iusticiam facere [...]" (p. 183).

48 "[...] prout ex insipiencia nostra spiritualiter delinquimus circa ea [temporalia] [...]" (p. 180).

49 "Sed iudex spiritualis et ecclesiasticus habebit huiusmodi iurisdiccionem, ne ipsa temporalis indebite accepta et inuste usurpata inferant malum animabus nostris et spiritibus nostris" (p. 180).

"Nam istud casuale quasi universale est, cum omnis quaestio et omne litigium habeat hoc casuale annexum, quod potest deferri cum denunciacione criminis. Propter quod hoc casuale ut respicit animas potest esse eque generale, sicut illud regulare quod respicit corpora. Rursus cum anima sit potencior corpore, istud casuale erit principalius, quam illud regulare" (p. 181).

"[...] distinguemus duplicem potestatem summi pontificis et duplicem eius iurisdictionem in temporalibus rebus: unam absolutam et aliam regulatam [...]" (p. 181). "Si ergo summus pontifex secundum suum posse absolutum et alias sine freno et sine capistro, ipse tamen debet sibi frenum et capistrum imponere, in se ipso observando leges et iura" (p. 181).

" $[$... $]$ sic distinguere possumus duplicem eius iurisdiccionem in temporalibus rebus: unam directam et regularem [...] alia [...] e st certis causis inspectis et casualis [...]" (p. 181). Cfr. supra, nota 20.

"[...] plenitudo potestatis est in aliquo agente, quando illud agens potest sine causa secunda, quicquid potest cum causa secunda" (p. 190).
} 
to de esta proposición es que ese agente tiene el poder en el que se concentra todo el poder: Luego lo hace en términos negativos: carece de plenitud de poder todo agente que no tiene el poder de efectuar sin causa segunda lo que puede con ella. ${ }^{56}$ Fundamento de esta última proposición es que el agente carece del poder en el que está concentrado todo el poder. Pero como el papa no solo tiene todo el poder espiritual, sino que además, en el orden temporal, tiene, además de la potestas regulata, una potestas absoluta que le permite actuar directamente en el orden temporal en casos excepcionales, por ello el papa tiene el poder de hacer sin causas segundas lo que podría hacer con ellas. De allí que el papa tenga plenitudo potestatis.

\section{Guillermo de Ockham: la caducidad del orden legal y el retorno al orden del derecho natural}

En algunas de sus obras, especialmente en el Breviloquium, Ockham no plantea - por lo menos no lo hace inicialmente - las bases y los fundamentos de su teoría política en términos estrictamente políticos, sino que presenta esos fundamentos en términos que hoy llamaríamos civiles. En efecto, en la construcción de las relaciones políticas Ockham no toma como punto de partida la relación de subordinación entre gobemantes y súbditos, sino la relación de posesión humana de las cosas. ${ }^{57}$ Miethke ha definido el problema en los siguientes términos: "[...] Ockham no comenzó a desarrollar su pensamiento político tomando como punto de partida las relaciones entre los hombres, sino - precisamente teorizando el problema de la posesión - la relación entre el hombre y las cosas". ${ }^{58}$

Por otra parte, además de retrotraer los fundamentos de su teoría política hacia un problema prepolítico - como es el problema de la posesión y la propiedad Ockham presenta su teoría política en un contexto absolutamente teológico, pues desarrolla el problema a partir de la situación del hombre en el paraíso, antes del pecado adánico. A partir de ese estadio Ockham analiza la posterior evolución histórica de la relación del hombre con las cosas y con los otros hombres, y lo hace definiendo ambas relaciones de modo diferente, siempre teniendo en cuenta el momento de la historia de la humanidad de que se trata.

En numerosos trabajos Jürgen Miethke ${ }^{59}$. ha llamado la atención sobre una intuición filosófica formulada por Ockham en las Quaestiones in librum IV Sententia-

\footnotetext{
56 "Quod si agens aliquod non habet tale posse, consequens est, quod non habeat plenum posse, quia non habet posse in quo reservatur omne posse" (p. 190).

Cfr. Breviloquium de potestate papae, Lib. III, cap. vii (en la ed.de L. Baudry, Paris, 1937, p. 85 s.)

58 Cfr. J. Miethke, "Libertad, propiedad y gobierno en el pensamiento político de Guillermo de Ockham", en: El hilo de Ariadna. Del tardo antiguo al tardomedioevo (compilado por H. Zurutuza, H. Botalla, F. Bertelloni.), Rosario, 1996, pp. 246/7.

59 Véase, por ejemplo, J. Miethke,op. cit., esp. p. 246: "[...] Dios dio al hombre todas las dotes necesarias para ciertas actividades: herramientas para caminar que le permitieron moverse, el intelecto para razonar, la voluntad para los actos de volición. Pero sin embargo no inspiró al hombre con el poder habitual para realizar esos actos. Con todo, era suficiente dotar al hombre con la posibilidad de adquirir semejante poder habitual".Véase tambien de Miethke, "Señorio y libertad en la teoria política del siglo XIV", en Patristica et Mediaevalia XVI (1995), pp. 3/32, esp. pp. 24 ss.
} 
rum, una obra de 1317. Según Miethke, esa intuición ejerció una fuerte influencia sobre el pensamiento político del venerabilis inceptor. Se trata de la doctrina acerca de la potestas, capacidad o posibilidad que Dios dio al hombre para que ejerza ciertos actos, es decir, para que convierta en actual o habitual esa posibilidad que, al serle entregada, aún era un simple principium operationis, es decir, puramente potencial.

De acuerdo con esta originaria intuición ockhamista, si bien Dios concede al hombre la posibilidad de que, mediante esas potestates o principii, pueda ejercer libremente los actos para cuyo ejercicio lo facultan esas potestates y principii, sin embargo Dios no dio al hombre el ejercicio concreto de esos actos. Dios le dio la potestas de ejercer estos actos, pero dejó en manos del hombre la definición misma del modo como ese poder sería llevado a cabo quedaba totalmente en manos del hombre. Al hombre le basta con poseer solamente la potestas. Con ella puede, él mismo, o bien ejercer la potestas efectiva y concretamente o bien no ejercerla. ${ }^{60}$ Es el hombre mismo el que, libremente, debe actualizar o no las posibilidades que, en forma de principios o posibilidades, le fueron entregadas por Dios.

Se trata de un intuición que delata una sensible influencia agustiniana sobre Ockham. Su estructura recuerda el modo como San Agustín describe la situación en la que Dios colocó a Adán: le otorgó todos los poderes, pero no todos los quereres. ${ }^{61}$ Los poderes facultaban al hombre para definir los quereres. Aunque contaba con el poder para definir bien su querer, la facultad de definirlo bien o mal no dependía de Dios sino del hombre. Ockham procede de modo similar. El hombre tenía potestates que eran dones divinos. Su actualización, sin embargo, no depende de un don divino sino de un acto humano.

Ockham, pues, desarrolla su pensamiento político como una teología de la relación del hombre con las cosas y con los hombres. De allí que nunca sea suficiente la insistencia en el hilo conductor que el venerabilis inceptor tomo como leit motiv fundamental del desarollo de su pensamiento político: Dios nunca dota al hombre con el ejercicio concreto de actos, sino que solo le otorga las posibilidades o potestates para que el hombre ejerza esos actos. Y esas potestates que el hombre recibe de Dios serán diferentes de acuerdo a los diferentes momentos de la historia humana que Ockham esté describiendo.

En primer lugar Ockham aplica su intuición de las potestates a la situación del hombre inmediatamente después de la creación, antes del pecado adánico. Para ello describe la situación del hombre anterior al pecado adánico. Ockham se refiere

$60 \quad$ "[...] in operibus naturae videmus frequenter quod Deus dat alicui principium operationis, et tamen non dat actualiter omnia necessaria ad illam operationem. Exemplum: Deus, creando hominem, dat sibi principium respectu actus sciendi et volendi, quia intellectum et voluntatem, et tamen non oportet quod det sibi habitus per quos potest faciliter in talia opera, sed sufficit quod det sibi potestatem adquirendi tales habitus. Ita in proposito, quando dat sibi principia per quae potest simpliciter in opera virtuosa et meritoria, non oportet quod det sibi omnia per quae potest in illa opera prompte et expedite, sed sufficit quod det sibi potestatem adquirendi sibi talia" (IV Sent., q. V, en: Quaestiones in Librum Quartum Sententiarum, ed. R. Wood \& G. Gál), q. V. en Guillelmi de Ockham Opera Philosophica et Theologica, St. Bonaventure, N. York, 1984, [OTh, VII, p. 51].

De Trinitate, $\mathrm{V}, 9,4$. 
a dos aspectos de este primer momento de la vida de la humanidad: uno, el de su relación con las cosas, otro, el de su relación con los hombres. Así dice, por una parte, que la humanidad antes del pecado se encontraba en una situación tan armónica y ausente de avaricia, que los hombres no necesitaban de la propiedad. ${ }^{62}$ Por ello, en este primer momento los hombres no discriminaron lo mio y lo tuyo, sino que solo poseyeron una potestas utendi entendida como capacidad de uso de las $\operatorname{cosas}^{63}$ Por la otra, y siempre como consecuencia de la armonía de una naturaleza íntegra, los hombres tampoco necesitaban gobierno, razón por la cual no existía el dominio del hombre sobre el hombre.

Luego describe la situación del hombre consecuente al pecado. En este caso Ockham se refiere nuevamente a los dos aspectos de la vida de relación de la humanidad: cosas y hombres. Por una parte, y en lo que concierne a la relación del hombre con las cosas, el hombre vuelve a recibir de Dios una capacidad o potestas, pero que ya no es la potestas utendi, sino la posibilidad de adquirir en propiedad que Ockham llama potestas appropiandi temporalia. ${ }^{64}$ No se trata aún de propiedad en acto, sino solo de la posibilidad de adquirir libremente en propiedad. Por ello el hombre puede efectivizar esa potestas adquiriendo propiedad, pero tambien puede rehusarse a adquirir en propiedad. Por la otra, en lo que concierne a la relación del hombre con los otros hombres, el hombre tambien recibe una potestas que concierne a la posibilidad de elegir gobernantes. Ockham la llama potestas instituendi rectores habentes iunsdictionem temporalem. ${ }^{65}$ Tambien en este caso, tratándose de una posibilidad, el hombre puede elegir gobernantes o no hacerlo.

Si nos internamos en algunos detalles concernientes tanto a la potestas appropiandi temporalia como a la potestas instituendi rectores habentes iunisdictionem temporalem en el segundo momento de la historia de la humanidad, i.e. en la vida histórica de la humanidad posterior al pecado adánico. ¿Qué sucede, según Ockham, si tanto de la realización efectiva de la potestas apropiandi temporalia como de la realización efectiva de la potestas instituendi rectores no resulta un bien para los hombres, i.e., si de la transformación de esas potestates o posibilidades en actualizaciones no resulta algo bueno y útil para los hombres - que es el fin para el cual Dios e otorgó esas potestates? ¿Qué sucede si tanto la propiedad como el gobierno no cumplen con sus objetivos funcionales que consisten en producir o causar un bien al hombre? En primer lugar, en lo que concierne a la propiedad, seguiré la interpretación de Miethke. Miethke ha leído la teoría ockhamista acerca de la efectivización de la propiedad como una teoría abierta al retorno a la situación previa a la efectivización de la propiedad si ésta se convierte en una institución contraria a las condiciones mínimas que estaban garantizadas por

\footnotetext{
62 "Propter hoc enim quod in eis nulla fuisset avaritia [...], nulla fuisset tunc necessitas vel utilitas habendi proprietatem [...]" (Breviloquium, p. 85).

63 "[...] potestas disponendi et utendi temporalibus rebus ad utilitatem suam" (ibid.)

64 lbid., p. 86 .

65 bid., p. 87
} 
el derecho natural a la potestas utendi común. En otros términos, si la potestas appropiandi ha sido concedida por Dioś al hombre, lo ha sido porque ella es una potestas cuya efectivización puede ser útil a la humanidad. Cuando el hombre efectiviza la potestas appropiandi, discrimina lo que es propiedad de cada uno e instituye legalmente lo que es dominium de este hombre y de aquél hombre Podría suceder, sin embargo, que de esta institución legal humana de la propiedad no se derive un bien para la humanidad y que, en consecuencia, la legalización de la propiedad se convierta en un obstáculo para la vida. En este caso, la vigencia del sistema legal de la propiedad no puede ser más fuerte que el derecho natural a la vida para el cual Dios había previsto, en el momento de la humanidad anterior al pecado, la potestas utendi común de todos los bienes necesarios para la vida. En caso de que resulte obstaculizado el derecho natural a la vida vigente en el hombre anterior al pecado y garantizado en ese estadio por la potestas utendi común, el derecho legal a la propiedad es neutralizado por el natural derecho a la vida. En este caso el hombre puede hacer caso omiso a la institucionalización legal de la propiedad y comer el pan del otro si está hambriento.

Si hacemos una lectura cuidadosa de esta situación, deberíamos decir que, en rigor, no es el hombre el que hace caso omiso a la institución legal de la propiedad, sino que es el mismo derecho natural el que, de suyo, anula el derecho legal. Por ello este derecho legal deja de existir tan pronto como no sirve para los fines para los cuales fue instituído. Trátese de una automática desaparición del derecho legal o de un cambio hecho por el hombre del sistema jurídico, de hecho en cualquiera de los dos casos el hombre debe atenerse al otro y único derecho que aún existe y que es más poderoso que el derecho legal: el hombre puede hacer valer su derecho natural a la vida recurriendo a la propiedad del otro. ¿Porqué? Porque el sistema legal de la propiedad queda neutralizado en virtud de su inutilidad para satisfacer el principio "derecho natural a la vida". Por ello ya no hay propiedad, sino que vuelve a regir el uso común, la potestas utendi común. En palabras de Miethke: cuando la propiedad legal atenta contra la vida, "[...] las barreras del derecho positivo se hacen permeables. El hambriento podrá tomar el pan de algún otro que lo tiene en abundancia y podrá salvarse de morir de frío tomando el abrigo de otro que lo necesita, y ello aún sin el consentimiento explícito del propietario". ${ }^{66}$

Debe quedar claro cuál es el principio en virtud del cual la propiedad legal cae y deja libre el espacio al retorno de la natural potestas utendi. El sistema legal resultante de la efectivización de la potestas apropiandi temporalia no cae porque sea un sistema abierto cuya efectivización o no efectivización dependa de la libertad del hombre. Es verdad que es un sistema abierto que en su concreción o no (franciscanismo y consecuente renuncia a la propiedad) depende de la libertad humana, pero el sistema legal no cae tanto porque sea libre, sino porque es un sistema de derecho legal y positivo secundario y derivado respecto del derecho 
natural a la vida garantizado por la potestas utendi. Si el sistema legal cae, cae porque es abierto, si es abierto lo es porque es de institución libre; si no fuera de institución libre sería necesario y no podría desaparecer. Pero la causa por la cual el sistema legal cae no parece residir en su libertad. La libertad/apertura del sistema constituye la condición ontológica que hace posible que el sistema se desmorone, i.e. que sea o no sea más, pero no se desmorona porque sea un sistema basado en la libertad del hombre, sino porque es neutralizado por la vigencia de un derecho anterior que irrumpe tan pronto como el sistema legal deja de cumplir su función. ${ }^{67}$

En este aspecto el pensamiento de Ockham se acerca al de Egidio.

Lo mismo sucede en relación con la potestas instituendi rectores habentes iunisdictionem temporalem. Si esa potestas ha sido concedida por Dios al hombre, lo ha sido como potestas, pero igual que en el caso de la propiedad, se trata de una potestas o posibilidad cuya efectivización Dios deja librada a la libertad humana. Es una potestas cuya efectivización puede ser útil a la humanidad ${ }^{68}$, pero ella sigue siendo, en cuanto potestas, una simple posibilidad que el hombre puede efectivizar o puede no efectivizar. ¿Cuál es ahora la estructura que, luego del paso de la ausencia de rectores a la institución de rectores, puede producir el retorno a la ausencia de rectores? En las Octo quaestiones Ockham escribe:

"En casos normales (regulariter) el rey está por encima del reino. Sin embargo, en ciertos casos [el rey] puede estar por debajo del reino, porque en caso de necesidad (casus necessitatis) el reino puede deponer al rey [...] y puede hacerlo en virtud de la vigencia del derecho natural" ${ }^{69}$

Ockham opone situaciones regulares a casos de necesidad o casos excepcionales. La estructura del texto, referida a la potestas instituendi rectores, es la misma que en el caso de la propiedad. Si de la institución legal de rectores, que es la situación que debe ser normal y regular, resulta un obstáculo para los fines para los cuales los rectores fueron instituidos; se verifica un casus necessitatis que justifica el retorno a la situación anterior a la institución legal de esos rectores: el mismo pueblo que instituyó los rectores puede recurrir a su derecho natural de instituir y en virtud de ese derecho natural de instituir puede deponer los rectores si éstos no corresponden a la funcionalidad del cargo para el cual fueron instituídos.

$67 \quad$ "[... [la] propiedad nunca es concedida por Dios para que ella entre en colisión con el fundamental derecho a la vida...la propiedad es un acuerdo razonable, una institución útil [...] pero [...] de ninguna manera es inderogable del mismo modo como no es indispensable" (Miethke, p. 247).

"[...] quia jurisdictio temporalis est de numero illorum que sunt necessaria et utilia ad bene et politice vivere [...]" (Breviloquium, p. 87).

69 Cfr. Octo quaestiones de potestate papae, II, 8. (en la ed. de H. S. Offler, Guillelmi de Ockham Opera Politica, Manchster, 1974, p. 83). 


\section{Conclusión}

Tanto la teoría egidiana del casus imminens como la teoria ockhamista del casus necessitatis constituyen dos formulaciones de carácter nomativo referidas al comportamiento del poder originario respecto de los poderes derivados. Casus imminens y casus necessitatis designan, cada uno de ellos, lo que debe suceder al nivel del poder político originario - de allí su carácter normativo - cuando el ejercicio de los poderes derivados del poder político originario no se adecúa o no corresponde a las funciones para las cuales esos poderes derivados fueron instituidos.

Es difícil asumir hoy el carácter normativo del casus imminens y del casus necessitatis, sobre todo cuando la estructura teórica y las circunstancias a partir de las cuales ambos casus fueron pensados por Egidio y Ockham no coinciden con la arquitectura de lo que llamamos el estado democrático. Es imposible, por ejemplo, pensar en términos normativos una estructura según la cual todos los poderes distribuidos de modo descendente, i.e. hacia abajo, se repliegan hacia su origen y se concentran en una sola instancia en virtud de una falla o de una deficiencia en el ejercicio de los poderes distribuídos.

Sin embargo, la politología contemporánea ha generado el concepto de déficit democrático con el que procura tipificar las situaciones anormales en las cuales tiene lugar, o bien una falencia de la vigencia de las instituciones especificas del orden democrático, o bien una ausencia de las instituciones que, según el orden constitucional, deben imperar regularmente en un estado de derecho. Suele describirse el déficit democrático como una situación en la cual, por motivos que no es el caso mencionar aquí, alguno de los poderes propios del estado de derecho asume las facultades de otro de esos poderes. Más aún, la misma dictadura podría constituir el caso absolutamente extremo y paradigmático de déficit democrático, ya que en ella todos los poderes del estado de derecho caducan y son asumidos por una instancia única que concentra los poderes suspendidos propios del orden jurídico regular.

Sin duda, comparados con la racionalidad interna de que goza el estado de derecho, los casos de déficit democrático constituyen paradigmas de irracionalidad, y ellos son tanto más acentuados cuando más acentuado es el déficit democrático que se registra en ellos. Pues existe, en efecto, una relación directamente proporcional entre el grado de déficit que suele padecer la democracia y el grado de irracionalidad que acompaña ese déficit.

Esta situación de irracionalidad ofrece una paradoja: por una parte, se trata de casos de irracionalidad, por la otra la teoría política no puede resignar sus aspiraciones de elaborar una teoría acerca de ellos. La paradoja consiste en que la teoría política aspira a formular en términos teóricos o conceptuales situaciones en las que la irracionalidad parece no ser compatible o no compadecerse con las teorías. Naturalmente, la incompatibilidad surge sobre todo cuando se trata de expresar una teoría del déficit democrático en términos normativos. En efecto, ¿cómo pue- 
de ser norma, lo que en sí mismo es irracional? ¿Cómo puede expresarse en términos conceptuales lo que la teoría política suele tipificar como la máxima irracionalidad de la teoría política, i.e. la neutralización del ejercicio de todos los poderes y su concentración en un poder único?

Creo que existe, sin embargo, la posibilidad de formular una teoría del déficit democrático utilizando las doctrinas que hemos analizado, pero sustituyendo su naturaleza de teorias de carácter normativo y transformándolas en esquemas de tipo descriptivo. Estos esquemas descriptivos de la lógica interna del estado de excepción constituyen esfuerzos de la razón para expresar en términos conceptuales lo que, presentado en términos normativos, aparece como irracional. 